substitute for lignum vitae in the heartwood of Xanthostemon verdugonianus, which weighs 77 pounds per cubic foot. The tree is large, with a diameter of 45 inches, and a length of stem of 25 to 30 feet. It occurs in the southern islands of the archipelago.

\section{Charles E. Bessey}

\section{UNIVERSITY OF NEBRASKA}

\section{SPECIAL ARTICLES}

A FOSSIL GAR-PIKE FROM UTAH

SoMre time ago Professor R. D. George obtained in Utah a fine specimen of Lepisosteus preserved in a block of limestone. The fossil is of particular interest because the stone is being quarried by the Western Lithographic Stone Company, yielding slabs highly serviceable for lithographic purposes. The age of the formation had not been determined until the fish was examined, but it is now safe to say that it is Middle or Lower Eocene. The specimen was obtained twelve feet from the surface, three miles northwest of Tucker, Utah. It lacks the head, but is otherwise in very good condition. In all respects, it agrees excellently with Lepisosteus simplex Leidy, as described and figured by Eastman. ${ }^{1}$ Eastman's excellent figure, except for having the head, might almost have been taken from our specimen. The smooth scales, with occasional minute pits, are in exact agreement, as are the characters of the fins, etc.

L. simplex was found in the typical Green River locality in Wyoming, according to Eastman, though Hay ascribes it to the Bridger Eocene. There is a species described from Utah, L. cuneatus (Cope), which has smooth scales, and it is at least very much like $L$. simplex. This $L$. cuneatus comes from the Manti shales, Manti being some fifty miles south-southwest of Tucker. Eastman (loc. cit.) ascribes this to the Miocene, but Cope considered it Eocene, and it has been held that the Manti shales are of the same age as the Green River. It may be that the true Green River extends from Wyoming to central Utah, and that $L$. cuneatus is the same as $L$. simplex.

\section{UNIVERSTTY OF Colorado}

T. D. A. Cockerelit

${ }^{1}$ Bull. Mus. Comp. Zool., XXXVI., No. 3.
THE NUCLEATION OF A CLOSE LECTURE ROOM

Recently, at the request of Professor Barus, I made a series of measurements on the nuclei in the air of a crowded lecture room. There were over, a hundred students in attendance and the ventilation was not sufficiently brisk to obviate the occurrence of somewhat offensive closeness at the end of the hour. The object of the investigation was to determine whether any solid or liquid nuclei were thrown off by the many lungs in action, sufficient to be detected by the coronas of the fog chamber in the presence of the natural nucleation (largely inorganic) of the lecture room.

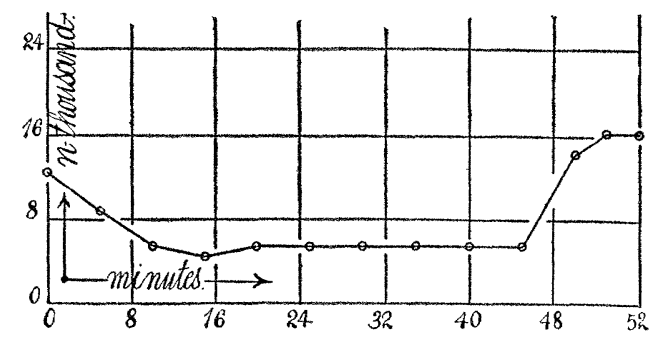

The method of investigation consisted in aspirating the air of the room continuously through the fog chamber and examining it by exhaustion from time to time. The result may best be given graphically by laying off the nuclei in thousands per cubic centimeter in a way to show their variation in the lapse of minutes of time.

The figure begins with a moderate measure of dust during the desultory entry of the members of the class. But throughout the lecture hour the nucleation diminishes. Evidently there is subsidence of dust (in part into the lungs of the students who virtually cushion the floor), but no corresponding evolution of nuclei as resulting from the respiration of this animated carpet. At the close of the lecture, when the class rises hilariously as a body to depart from the place of torment, they literally raise the dust again, in much larger quantity than on entering.

Unfortunately it is impossible to separate the organic from the inorganic dust content of this atmosphere for the present purposes. The only conclusion attainable is, therefore, that there is no appreciable evolution of non-gaseous matter, but rather an absorption of nuclei 
by the respiration of a hundred active lungs, even when the closeness of the air becomes oppressive. The possibility of recognizing spore production, however minute, from cultures made in dust-free air, may not be without interest.

BRowN UNIVERSITY, Laura C. Brant Providence, R. I.

\section{SOCIETIES AND ACADEMIES \\ THE AMERTCAN MATHEMATICAL SOCIETY}

The one hundred and forty-third regular meeting of the society was held at Columbia University on Saturday, April 24, 1909, extending through a morning and an afternoon session. The attendance was about thirty-five persons, including twenty-six members of the society. President Bôcher occupied the chair, being relieved at the afternoon session by Vice-President Kasner. The council announced the election of the following persons to membership in the society: Miss W. B. Bauer, High School, Topeka, Kan.; Mr. W. W. Denton, University of Illinois; Mr. Meyer Gaba, University of Kansas; Professor W. H. Garrett, Baker University; Miss S. E. Graham, High School, Topeka, Kan.; Mr. G. F. Gundelfinger, Sheffield Scientific School; Professor W. A. Harshbarger, Washburn College; Mr. L. T. W. Hogrefe, Milwaukee, Wis.; Professor L. A. Howland, Wesleyan University; Mr. George Melcher, State Normal School, Springfield, Mo. Three applications for membership in the society were received.

Professor H. S. White was reelected a member of the editorial committee of the Transactions for a term of three years beginning October 1, 1909.

The following papers were read at this meeting:

R. D. Carmichael: "On certain functional equations."

R. D. Carmichael: "Note on some polynomials related to Legendre's coefficients."

W. H. Jackson: "A theorem concerning simple continued fractions."

W. H. Jackson: "Shadow rails."

L. P. Eisenhart: "The twelve surfaces of Darboux and the transformations of Moutard."

W. F. Osgood: "On Cantor's theorem concerning the coefficients of a convergent trigonometric series, with generalizations."

L. S. Dederick: "Certain singularities of transformations of two real variables."

Paul Saurel: "On Fredholm's equation."

J. E. Wright: "On abelian functions of genus 3."
J. C. Morehead: "A simplification of Lagrange's method for the solution of numerical equations (second paper)."

A. S. Chessin: "On gyroscopic couples."

Edward Kasner: "The interpretation of differential equations in line coordinates."

E. D. Roe, Jr.: "On the extension of the ex* ponential theorem."

Mr. Dederick's paper was presented to the society through Professor Bouton. In the absence of the authors Mr. Dederick's paper was read by Professor Bôcher, and the papers of Professors Carmichael, Saurel, Chessin, Kasner and Roe, and Dr. Morehead were read by title.

The Chicago section of the society held its spring meeting at the University of Chicago on Friday and Saturday, April 9-10. The summer meeting and colloquium of the society will be held at Princeton University in the week September 13-18.

$$
\begin{aligned}
& \text { F. N. CoLE, } \\
& \text { Secretary }
\end{aligned}
$$

\section{THE UTAF ACADEMY OF SCIENCES}

THE second annual meeting of the Utah Academy of Sciences was held in the auditorium of the Packard Library, Salt Lake City, on Friday. evening, April 9, and Saturday afternoon, April 10.

The Friday evening meeting was a "Darwin Centennial" memorial, as indicated by the program:

"Darwin the Man," by Professor W. W. Henderson.

"Factors in Zoological Evolution," by Dr. John Sundwall.

"Factors in Botanical Evolution," by Dr. C. T. Vorhies.

Discussion, led by Dr. E. D. Ball.

The saturday afternoon program consisted of the following papers:

"The Adaptation of Insects, with Special Reference to Arid Conditions," by Dr. E. D. Ball.

"The Alfalfa Leaf Weevil," by Professor E. G. Titus.

"The Honey Ants of Utah," by A. O. Garrett. "Orbital Glands of Amphibians," by P. G. Snow.

"Note on Geological Survey Bulletin No. 371," by J. B. Forrester.

"High Temperature Measurement," by Dr. L. W. Hartman.

"Pottery Glaze Coloring," by A. F. GreavesWalker. 